\title{
Alteração do período anterior à interferência da soja na presença de plantas voluntárias de milho ${ }^{1}$
}

\section{Alteration of period before the interference of soybean on presence of volunteer corn}

\author{
Theodoro Schneider ${ }^{2}$; Ana Paula Rockenbach ${ }^{3}$; Mario Antonio Bianchi ${ }^{4}$
}

\begin{abstract}
Resumo - Objetivou-se com este trabalho caracterizar o início da interferência de plantas daninhas em dois cultivares de soja, com ciclo de crescimento distinto, sob duas condições de infestação de plantas de milho. O delineamento experimental foi blocos casualizados, em esquema de parcelas subdivididas, composto por dois fatores: períodos de convivência da soja com o milho (sem convivência, convivência por 14, 28 e 42 dias após a semeadura (DAS) e por todo o ciclo da cultura) e densidades de plantas de milho, 10 plantas $\mathrm{m}^{-2}$ e 30 plantas $\mathrm{m}^{-2}$. O cultivar Fundacep 63RR sofreu alterações no crescimento em períodos iguais ou superiores a 42 DAS, independente das populações de plantas de milho. A redução na produtividade de grãos de soja ocorreu aos 28 DAS para a população de 10 plantas $\mathrm{m}^{-2} \mathrm{e}$ aos 14 DAS para a população de 30 plantas $\mathrm{m}^{-2}$. No cultivar Fundacep 59RR, as alterações nas características morfológicas nas plantas de soja ocorreram em períodos de convivência iguais ou superiores a 28 DAS e a população de plantas de milho de 30 plantas $\mathrm{m}^{-2}$ alterou a estatura e o número de ramos aos 60 DAS. Neste cultivar a redução de produtividade iniciou aos 42 DAS para a população de 10 plantas $\mathrm{m}^{-2}$ e aos 28 DAS para a população de 30 plantas $\mathrm{m}^{-2}$ de milho.
\end{abstract}

Palavras-chaves: competição, convivência, Glycine max, Zea mays

\begin{abstract}
The aim of this work was to characterize the onset of weed interference in two soybean cultivars, with different growth cycle, under two conditions of corn plants infestation. The experimental design was split plot design composed by two factors: periods of coexistence of soybean with corn (no coexistence, coexistence during 14, 28 and 42 days after sowing (DAS) and throughout the soybean cycle) and two corn densities: 10 plants $\mathrm{m}^{-2}$ and 30 plants $\mathrm{m}^{-2}$. The cultivar Fundacep 63RR had its growth altered in period equal or longer than 42 DAS with no relation to corn populations. The reduction in grain yield of soybean occurred at 28 DAS for 10 plants $\mathrm{m}^{-2}$ density and 14 DAS for 30 plants $\mathrm{m}^{-2}$. The cultivar Fundacep 59RR changed its morphological characteristics in period equal or longer than 28 DAS. With 30 plants $\mathrm{m}^{-2}$ of corn the height and number of soybean branches changed at 60 DAP. For the same cultivar, the yield loss started at 42 DAS for 10 plants $\mathrm{m}^{-2}$ of corn and 28 DAP for 30 plants $\mathrm{m}^{-2}$.

Keywords: competition, coexistence, Glycine max, Zea mays

\footnotetext{
${ }^{1}$ Recebido para publicação em 29/04/2014 e aceito em 09/07/2015.

${ }^{2}$ Doutorando em Agronomia - Universidade de Passo Fundo. Passo Fundo, Rio Grande do Sul, Brasil. theodoroschneider@hotmail.com (*autor para correspondência)

${ }^{3}$ Doutoranda em Agronomia - Universidade de Passo Fundo. Passo Fundo, Rio Grande do Sul, Brasil.

${ }^{4}$ Pesquisador e Professor - CCGL-Tec/Universidade de Cruz Alta, Cruz Alta, Rio Grande do Sul, Brasil.
} 


\section{Introdução}

A competição é uma interação negativa que ocorre quando dois ou mais indivíduos utilizam recursos em suprimento escasso no ambiente em que convivem (Radosevich et al., 2007). A produtividade de grãos de soja é reduzida devido à competição com plantas daninhas, como verificado na presença de nabo forrageiro (Raphanus sativus) (Bianchi et al., 2011), picão-preto (Bidens pilosa e $B$. subalternans), capim-amoroso (Cenchrus echinatus) (Nepomuceno et al., 2007), caruru (Amaranthus rudis) (Steckel e Sprage, 2004) e de milho voluntário (Zea mays) (Marquardt et al., 2012a).

$\mathrm{Na}$ agricultura atual a cultura da soja tem sido extremamente dependente do uso de herbicidas para o controle de plantas daninhas. No entanto, há a necessidade de adotar tecnologias que torne o cultivo menos dependente do uso deste insumo visando a redução dos impactos negativos causados pelo uso excessivo dessa ferramenta. O conhecimento sobre os períodos de competição das plantas daninhas nas culturas auxilia na escolha do momento mais adequado para empregarmos medidas de controle (Radosevich et al., 2007).

O período anterior a interferência pode ser alterado tanto pelas características do cultivar como pela população de plantas daninhas. Em soja, cultivares precoces e de porte baixo apresentam baixa capacidade de competição e os cultivares tardios e de porte alto são mais competitivos com plantas daninhas (Lamego et al., 2004). O período anterior à interferência (PAI) altera-se significativamente com o incremento da densidade de plantas daninhas (Silva et al., 2009a).

Atualmente, na cultura da soja existe forte tendência de redução de densidades de semeadura e de uso de cultivares com ciclo de crescimento precoce (por exemplo, 110 dias), com estatura e área foliar reduzidas. Isso resulta na redução da habilidade competitiva da cultura frente às espécies daninhas e torna os cultivares de soja mais dependente do controle químico eficaz. Carvalho e Velini (2001) observaram que a presença de plantas daninhas modificou o período de fechamento da entrelinha e também a morfologia da cultura da soja, sendo que na menor densidade de plantas daninhas $o$ fechamento da entrelinha foi antecipado. Plantas de soja com maior potencial de desenvolvimento e produtividade possuem habilidade competitiva superior a naboforrageiro, picão-preto e guanxuma (Bianchi et al., 2006).

Com o advento do cultivo de milho com a tecnologia Roundup Ready® (RR) é previsível que por reflexo da perda de grãos ou partes de espigas na colheita do milho, ocorra à emergência de plantas voluntárias na cultura da soja RR, tornando-se planta daninha.

Vários estudos visando à determinação do PAI em diversas culturas já foram realizados, no entanto, novos trabalhos são necessários uma vez que as práticas de cultivo de soja sofrem constantes mudanças. Assim, objetivou-se com este trabalho caracterizar o início da interferência em dois cultivares de soja em função da população da espécie daninha, com base na hipótese do cultivar de ciclo tardio possuir maior habilidade competitiva e ter o PAI mais prolongado que no cultivar de ciclo superprecoce.

\section{Material e Métodos}

Foram conduzidos dois experimentos a campo, no ano agrícola de 2010/2011 em Cruz Alta, situado na região noroeste do estado do Rio Grande do Sul. A área experimental situase na latitude de $28^{\circ} 33^{\prime} 41,30^{\prime \prime} S$ e longitude de $53^{\circ} 37^{\prime} 18,61^{\prime \prime} O$, sendo a altitude média de 444 $m$ e o solo classificado como Latossolo Vermelho Distrófico (Embrapa, 1999). A precipitação pluvial média anual da região é de $1.800 \mathrm{~mm}$ e as temperaturas médias anuais situam-se entre $13,3{ }^{\circ} \mathrm{C}$, no mês mais frio, e 24,6 ${ }^{\circ} \mathrm{C}$, no mês mais quente (CEMETRS, 2011). O clima da região enquadra-se na categoria Cfa, segundo a classificação de Köppen adaptado por 
Moreno (1961), ou seja, subtropical úmido com verões quentes. A área experimental tem sido manejada sob sistema de plantio direto consolidado, sendo que para a instalação do experimento foi realizada dessecação da cobertura vegetal, a fim de eliminar as plantas daninhas presentes na área.

Um experimento foi conduzido com o cultivar de soja Fundacep 63RR e o outro com o cultivar Fundacep 59RR. O Fundacep 63RR se caracteriza por pertencer à grupo de maturação 5,0 sendo caracterizado como super-precoce e hábito de crescimento indeterminado. O cultivar Fundacep 59RR se caracteriza por pertencer ao grupo de maturação 7,5 sendo caracterizado como tardio e hábito de crescimento determinado.

O delineamento experimental utilizado foi de blocos ao acaso, com quatro repetições. Os tratamentos foram arranjados em esquema de parcelas subdivididas, sendo que cada unidade experimental ocupou a área de $18 \mathrm{~m}^{2}$ (6 x $3 \mathrm{~m}$ ). Foram avaliados dois fatores: períodos de convivência da soja com plantas daninhas (sem convivência, convivência por 14, 28 e 42 dias após a semeadura e por todo o ciclo da cultura), perfazendo a parcela principal e densidades de plantas milho RR (10 plantas $\mathrm{m}^{-2}$ e 30 plantas $\mathrm{m}^{-2}$ ), perfazendo as subparcelas. No período sem convivência a cultura foi mantida livre de plantas daninhas, nos demais, a cultura permaneceu na presença somente do milho RR até os períodos pré-determinados ou por todo o ciclo de desenvolvimento. Em média, o estágio de desenvolvimento das plantas de soja aos 14, 28 e 42 dias após a emergência foram V3, V5 e V9 respectivamente e o milho apresentava nas mesmas épocas, 4, 7 e 9 folhas respectivamente (considerando a última folha decumbente).

A semeadura da soja foi realizada no dia 15 de novembro de 2010, utilizando-se semeadora regulada com espaçamento de 0,45 me distribuição de 17 sementes $\mathrm{m}^{-1}$, visando atingir uma população de 34 plantas $\mathrm{m}^{-2}$. A adubação e demais tratos culturais realizados seguiram as indicações técnicas para a cultura (Reunião, 2010).

Foi escolhido o milho RR como modelo de planta daninha por ser uma espécie que compete com soja semeada imediatamente após a colheita do milho e por manter a competição uniforme devido ao controle da densidade desejada e facilitando o controle das demais plantas daninhas na cultura da soja.

O milho híbrido foi semeado manualmente nas entrelinhas da cultura no mesmo dia da semeadura da mesma. A eliminação do milho para a determinação de cada período de convivência foi realizada com a aplicação do herbicida clethodim $\left(72 \mathrm{~g} \mathrm{ha}^{-1}\right) \mathrm{e}$ das demais plantas daninhas com a aplicação do glyphosate $\left(720 \mathrm{~g}\right.$ de equivalente ácido $\left.\mathrm{ha}^{-1}\right)$. Quando necessário foi reaplicado o glyphosate para manter os tratamentos livres da interferência de plantas daninhas.

Aos 60 dias após a semeadura da soja (DAS) foi determinado a estatura de planta, o número de nós e o número de ramos. Na maturação, além dessas variáveis, foi determinado o comprimento médio dos ramos (CMR). Essas determinações foram realizadas numa amostra de 10 plantas em cada parcela. A produtividade dos grãos de soja foi determinada pela colheita da área útil da parcela (duas fileiras centrais espaçadas em $0,45 \mathrm{~m}$ com $4 \mathrm{~m}$ de comprimento), trilha, limpeza e determinação da massa de grãos, sendo os resultados corrigidos para $13 \%$ de umidade e transformados em $\mathrm{kg} \mathrm{ha}^{-1}$.

Os dados obtidos foram submetidos à análise de variância e para diferenças significativas pelo teste $\mathrm{F}$, a $5 \%$ de probabilidade do erro, as médias dos tratamentos foram comparadas utilizando-se o teste de Tukey a 5\% de probabilidade do erro.

\section{Resultados e Discussão}

No cultivar de ciclo super-precoce, Fundacep 63RR, as densidades de plantas de milho não alteraram a estatura de planta, número de nós, número de ramos e CMR, 
porém, os períodos de convivência com o milho causaram modificações nessas variáveis (Tabela 1). A convivência com milho até a avaliação realizada aos 60DAS (convivência total) estimulou o crescimento em estatura, mas na maturação não houve efeito diferenciado entre os períodos de convivência. Em geral, para as variáveis número de nós, número de ramos e CMR, houve redução nos valores a partir de 42 DAS ou somente na convivência total.

Tabela 1. Estatura $(\mathrm{cm})$, número de nós (nós planta $\left.{ }^{-1}\right)$, número de ramos $\left(\right.$ ramos planta $\left.^{-1}\right)$ e comprimento médio dos ramos - CMR ( $\mathrm{cm}_{\text {planta }}{ }^{-1}$ ) da soja, cultivar Fundacep 63RR, aos 60 dias após a semeadura e na maturação, em função de períodos de convivência e de densidades das plantas de milho. Cruz Alta-RS, 2011.

\begin{tabular}{lcrrrrrr}
\hline \multirow{2}{*}{ Fatores } & \multicolumn{2}{c}{ 60 dias após a semeadura } \\
\cline { 2 - 8 } & Estatura & Nós & Ramos & Estatura & Nós & Ramos & CMR \\
\hline 0 DAS & \multicolumn{7}{c}{ Convivência } \\
14 DAS & $71,5 \mathrm{~b}^{3}$ & $9,9 \mathrm{a}$ & $2,9 \mathrm{a}$ & $102,7 \mathrm{a}$ & $16,1 \mathrm{a}$ & $2,3 \mathrm{a}$ & $22,9 \mathrm{a}$ \\
28 DAS & $71,3 \mathrm{~b}$ & $10,0 \mathrm{a}$ & $1,7 \mathrm{a}$ & $101,5 \mathrm{a}$ & $16,2 \mathrm{a}$ & $3,0 \mathrm{a}$ & $25,6 \mathrm{a}$ \\
42 DAS & $69,9 \mathrm{~b}$ & $9,7 \mathrm{ab}$ & $1,4 \mathrm{ab}$ & $99,0 \mathrm{a}$ & $15,8 \mathrm{ab}$ & $2,3 \mathrm{a}$ & $21,3 \mathrm{ab}$ \\
Total & $76,9 \mathrm{~b}$ & $9,3 \mathrm{ab}$ & $0,9 \mathrm{~b}$ & $98,1 \mathrm{a}$ & $14,5 \mathrm{~b}$ & $2,0 \mathrm{a}$ & $12,4 \mathrm{bc}$ \\
\hline C.V. $(\%)$ & $85,3 \mathrm{a}$ & $9,1 \mathrm{~b}$ & $0,4 \mathrm{c}$ & $96,5 \mathrm{a}$ & $12,2 \mathrm{c}$ & $0,9 \mathrm{a}$ & $10,8 \mathrm{c}$ \\
\hline & 7,0 & 5,5 & 38,4 & 5,3 & 7,0 & 34,7 & 32,7 \\
\hline 10 plantas $\mathrm{m}^{-2}$ & $74,5 \mathrm{a}$ & $9,8 \mathrm{a}$ & $0,7 \mathrm{a}$ & $101,1 \mathrm{a}$ & $15,1 \mathrm{a}$ & $2,1 \mathrm{a}$ & $17,8 \mathrm{a}$ \\
30 plantas $\mathrm{m}^{-2}$ & $75,5 \mathrm{a}$ & $9,4 \mathrm{a}$ & $0,2 \mathrm{a}$ & $98,0 \mathrm{a}$ & $14,8 \mathrm{a}$ & $2,1 \mathrm{a}$ & $19,3 \mathrm{a}$ \\
\hline C.V. $(\%)$ & 2,9 & 9,4 & 33,6 & 4,4 & 9,4 & 54,3 & 23,5 \\
\hline
\end{tabular}

${ }^{1}$ DAS = dias após a semeadura; ${ }^{2}$ Convivência por todo o ciclo da cultura; ${ }^{3}$ Médias seguidas da mesma letra na coluna, dentro de cada fator, não diferem entre si pelo teste de Tukey $(\mathrm{p}=0,05)$.

No cultivar de ciclo tardio, Fundacep 59RR, a densidade de 30 plantas de plantas de milho $\mathrm{m}^{-2}$ causou aumento da estatura e redução do número de ramos das plantas de soja aos 60 DAS, já as demais variáveis não foram alteradas por este fator (Tabela 2). Houve estímulo ao crescimento em estatura na avaliação realizada aos 60 DAS para convivência até 42 DAS e na maturação para convivência total. Para as demais variáveis os períodos de convivência causaram redução nos valores determinados.

$\mathrm{Na}$ avaliação aos 60 DAS houve redução do número de nós e do número de ramos a partir de 28 DAS de convivência com milho (Tabela 3). Na maturação, a convivência com milho resultou na redução das variáveis, número de nós a partir de 28 DAS de convivência, CMR a partir de 42 DAS de convivência e número de ramos para convivência total. Alterações de plasticidade em plantas sob competição foram também observadas em Ammannia baccifera competindo com a cultura do arroz, havendo redução no número de folhas, estatura e biomassa total da planta (Chauhan, 2013).

Para Silva et al. (2009b) os componentes de rendimento foram os mais afetados pela competição, sendo que o número de grãos por vagem e a massa de mil grãos mostraram-se menos responsivos aos efeitos da competição, no entanto para produtividade o PAI em sistema de semeadura convencional ocorreu aos 12 dias após a emergência e no sistema de semeadura direta aos 17 dias após a emergência. No presente estudo, a análise das características de crescimento (estatura, número de nós e de ramos, CMR) indica que modificações nas plantas de soja do cultivar super-precoce ocorreram com períodos de convivência iguais ou superiores a 42 DAS e que a população de plantas de milho de 10 e 30 plantas $\mathrm{m}^{-2}$ não 
alterou essas características. No cultivar tardio, as alterações nas plantas de soja ocorrem em períodos de convivência iguais ou superiores a 28 DAS e a população de plantas de milho de 30 plantas $\mathrm{m}^{-2}$ alterou a estatura e o número de ramos aos 60 DAS. Esperava-se alterações consistentes nas variáveis determinadas neste trabalho para indicar o PAI dos cultivares.
Mesmo que cultivares precoces sejam menos competitivos que os tardios (Lamego et al., 2004), neste trabalho essas diferenças não foram verificadas nas características avaliadas, o que não permite indicar o PAI somente com base nas características morfológicas, mas sim com maior consistência na análise da produtividade de grãos.

Tabela 2. Estatura (cm), número de nós (nós planta ${ }^{-1}$ ), número de ramos $\left(\right.$ ramos planta $^{-1}$ ) e comprimento médio dos ramos - CMR ( $\mathrm{cm} \mathrm{planta}^{-1}$ ) da soja, cultivar Fundacep 59RR, aos 60 dias após a semeadura e na maturação, em função de períodos de convivência e de densidades das plantas de milho. Cruz Alta-RS, 2011.

\begin{tabular}{|c|c|c|c|c|c|c|c|}
\hline \multirow{2}{*}{ Fatores } & \multicolumn{3}{|c|}{60 dias após a semeadura } & \multicolumn{4}{|c|}{ Maturação } \\
\hline & Estatura & Nós & Ramos & Estatura & Nós & Ramos & CMR \\
\hline \multicolumn{8}{|c|}{ Convivência } \\
\hline $0 \mathrm{DAS}^{1}$ & $63,7 c^{3}$ & $10,7 \mathrm{a}$ & $3,1 \mathrm{ab}$ & $93,2 \mathrm{~b}$ & $18,1 \mathrm{a}$ & $5,8 \mathrm{a}$ & $39,0 \mathrm{a}$ \\
\hline 14 DAS & $66,0 \mathrm{c}$ & $10,6 \mathrm{ab}$ & $3,5 \mathrm{a}$ & $95,2 \mathrm{~b}$ & $17,7 \mathrm{ab}$ & $6,4 \mathrm{a}$ & $36,1 \mathrm{ab}$ \\
\hline $28 \mathrm{DAS}$ & $62,7 \mathrm{c}$ & $9,7 \mathrm{bc}$ & $2,7 \mathrm{~b}$ & $83,3 \mathrm{c}$ & $16,2 b$ & $5,9 \mathrm{a}$ & $38,2 \mathrm{ab}$ \\
\hline 42 DAS & $70,0 \mathrm{~b}$ & $8,9 \mathrm{~cd}$ & $1,0 \mathrm{c}$ & $93,5 \mathrm{~b}$ & $16,1 b$ & $5,9 \mathrm{a}$ & $29,9 \mathrm{bc}$ \\
\hline Total $^{2}$ & $75,2 \mathrm{a}$ & $8,6 \mathrm{~d}$ & $0,2 \mathrm{~d}$ & $105,1 \mathrm{a}$ & $14,1 \mathrm{c}$ & $2,3 \mathrm{~b}$ & $21,6 \mathrm{c}$ \\
\hline C.V. (\%) & 3,5 & 6,8 & 23,2 & 5,6 & 7,8 & 22,0 & 18,2 \\
\hline \multicolumn{8}{|c|}{ Densidades } \\
\hline 10 plantas $\mathrm{m}^{-2}$ & $66,3 \mathrm{~b}$ & $9,9 \mathrm{a}$ & $2,4 \mathrm{a}$ & $94,6 \mathrm{a}$ & $16,8 \mathrm{a}$ & $5,2 \mathrm{a}$ & $33,7 \mathrm{a}$ \\
\hline 30 plantas $\mathrm{m}^{-2}$ & $69,1 \mathrm{a}$ & $9,5 \mathrm{a}$ & $1,8 \mathrm{~b}$ & $93,5 \mathrm{a}$ & $16,0 \mathrm{a}$ & $5,5 \mathrm{a}$ & $32,2 \mathrm{a}$ \\
\hline C.V. (\%) & 4,0 & 5,0 & 22,7 & 1,9 & 9,6 & 15,6 & 32,8 \\
\hline
\end{tabular}

Tabela 3. Produtividade de grãos de soja, cultivar Fundacep 63RR, em função dos períodos de convivência e das densidades das plantas de milho. Cruz Alta, RS, 2011.

\begin{tabular}{|c|c|c|c|}
\hline \multirow{2}{*}{ Períodos de convivência } & \multicolumn{3}{|c|}{ Densidade de plantas de milho } \\
\hline & 10 plantas $\mathrm{m}^{-2}$ & \multicolumn{2}{|c|}{30 plantas $\mathrm{m}^{-2}$} \\
\hline $0 \mathrm{DAS}^{1}$ & A $3075 a^{3}$ & A 3059 & a \\
\hline 14 DAS & A 2966 a & A 3019 & a \\
\hline $28 \mathrm{DAS}$ & A 3050 a & B 2617 & $\mathrm{~b}$ \\
\hline $42 \mathrm{DAS}$ & A $2505 \quad b$ & B 2152 & $\mathrm{c}$ \\
\hline Total $^{2}$ & A712 c & B467 & $\mathrm{d}$ \\
\hline \multicolumn{4}{|c|}{ Coeficiente de variação para densidades $\quad 4,4 \%$} \\
\hline \multicolumn{2}{|c|}{ Coeficiente de variação para períodos de convivência } & $5,7 \%$ & \\
\hline
\end{tabular}

Para o cultivar Fundacep 63RR a maior densidade de plantas de milho reduziu produtividade de grãos de soja a partir do período de convivência de 28 dias após a semeadura da soja (DAS) (Tabela 3). Para o cultivar Fundacep 59RR ocorreu redução na 
produtividade de grãos a partir de 42 DAS, com 30 plantas de milho $\mathrm{m}^{-2}$ (Tabela 4 ).

Nos dois cultivares $\mathrm{o}$ aumento da densidade de milho, resultou em redução de produtividade de grãos de soja, porém em períodos diferentes. $\mathrm{O}$ aumento na densidade da espécie daninha resulta em maior perda de produção. Marquart et al. (2012a) notaram que a produtividade de grãos de soja reduziu $10 \%$ quando a soja competiu com milho voluntário na densidade de 0,5 plantas $\mathrm{m}^{-2}$ e $41 \%$ quando a competição foi com 16 plantas $\mathrm{m}^{-2}$. No presente estudo, ocorreram perdas de produção nos dois cultivares, contudo, as perdas ocorreram mais cedo no cultivar super-precoce. Pode-se supor que existe diferença na resposta dos cultivares à competição com plantas de milho, indicando habilidade competitiva diferenciada. Para Lamego et al. (2004) os cultivares precoces são menos competitivos que os tardios, resposta que se confirma neste trabalho em que o cultivar precoce Fundacep 63RR sofreu a competição mais cedo que o cultivar tardio Fundacep59RR.

O PAI foi alterado em função da densidade de plantas de milho. No cultivar Fundacep 63RR o PAI na densidade de 10 plantas $\mathrm{m}^{-2}$ foi de 28 DAS e na densidade de 30 plantas $\mathrm{m}^{-2}$ de 14 DAS (Tabela 3). Já com o cultivar Fundacep 59RR o PAI na densidade de 10 plantas $\mathrm{m}^{-2}$ foi de 42 DAS e na densidade de 30 plantas $\mathrm{m}^{-2}$ foi de 28 DAS (Tabela 4). Para Silva et al. (2009a) o PAI depende da quantidade de plantas daninhas. Esses autores encontraram PAI, para baixa, média e alta infestação de plantas daninhas, de 11 e 24 DAS, 11 e 15 DAS e 11 e 16 DAS, considerando 5 e $10 \%$ de tolerância na redução da produtividade da soja, respectivamente. O PAI também é variável entre cultivares, sendo para IAC 11 de 49 dias após a emergência (Carvalho e Velini, 2001), para BRS 133 de 11 dias após a emergência (Meschede et al., 2002) e para Monsoy 7988RR de 25 dias após a emergência (Benedetti et al., 2009).

Nos dois experimentos a semeadura da soja ocorreu no mesmo dia, permitindo especular que as diferenças entre cultivares indicam que o cultivar de ciclo tardio (Fundacep $59 \mathrm{RR}$ ) é mais tolerante à competição por que tem um PAI maior que o cultivar precoce (Fundacep 63 RR).

Tabela 4.Produtividade de grãos de soja, cultivar Fundacep 59RR, em função dos períodos de convivência e das densidades das plantas de milho. Cruz Alta, RS, 2011.

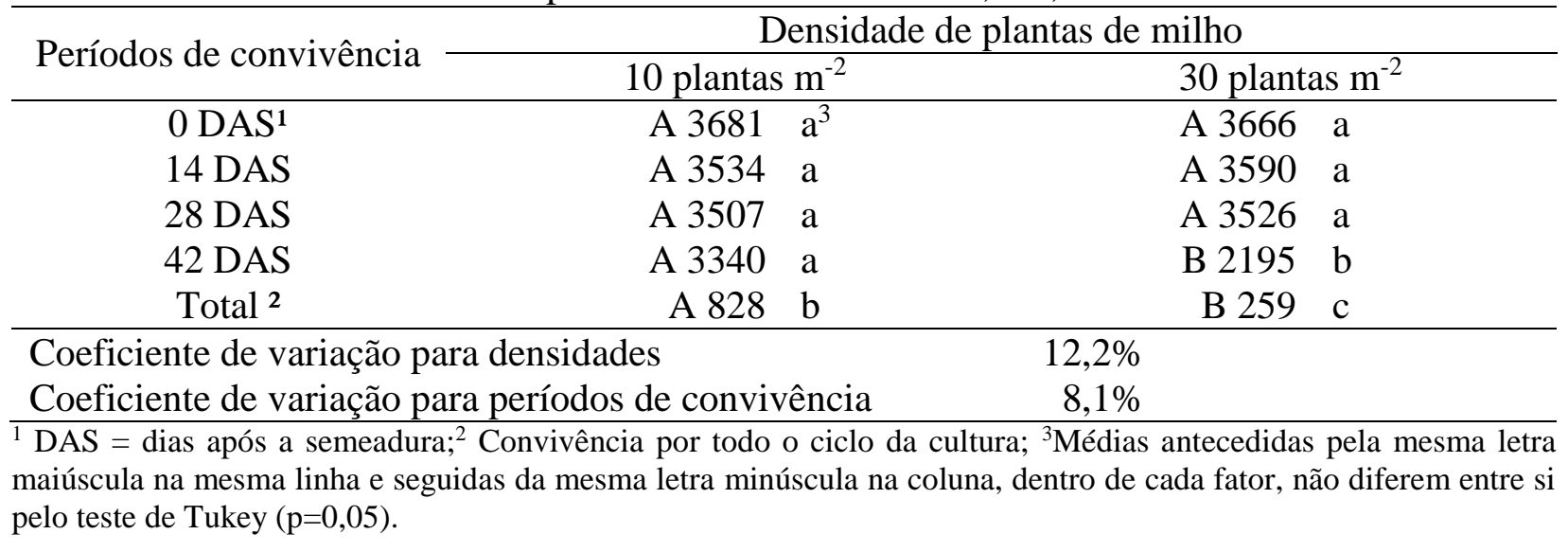

A presença de plantas voluntárias de milho com a tecnologia Roundup Ready ${ }^{\circledR}$ em lavouras de soja RR, pode causar prejuízos mesmo em baixas densidades, conforme Marquardt et al. (2012a) e Marquardt et al. (2012b). Em lavouras comerciais, dificilmente ocorrerão altas densidades de plantas de milho durante todo o ciclo de desenvolvimento, em decorrência do controle adotado. É durante fase vegetativa que se estabelecem as relações de 
competição que tem maior efeito sobre a produtividade de grãos de soja, existindo a necessidade da cultura ser mantida no limpo, em geral, dos 20 aos 50 dias após a emergência para minimizar as perdas decorrentes da competição com plantas daninhas (Pitelli, 1985). Uma cultura mais competitiva assume maior importância na agricultura atual, principalmente sob o ponto de vista da menor necessidade de uso de herbicidas maquinário, mão-de-obra e recursos naturais.

A vantagem da utilização de cultivares competitivos aumenta quando o controle químico das plantas daninhas tem sua eficiência reduzida, o que pode ocorrer devido ao estágio de aplicação inadequado, condições ambientais desfavoráveis ou até mesmo pela falta de opção de herbicidas para aplicação em pós-emergência da cultura. Além disso, cultivar mais competitivo poderá atrasar o início da competição, de forma que o controle de plantas daninhas poderá ser realizado mais tarde ampliando a janela de aplicação. No entanto, o agricultor certamente não escolherá um cultivar por ser mais competitivo e sim por possuir potencial produtivo mais alto. Assim o desafio é combinar cultivar com alto potencial produtivo com alta habilidade competitiva com plantas daninhas e/ou ajustar o manejo de plantas daninhas de modo a manter o potencial produtivo de cultivares com baixa habilidade competitiva.

\section{Conclusões}

Tanto para o cultivar Fundacep 63RR como para o Fundacep 59 RR, a alteração na produtividade de grãos se dá mais precocemente para maior população da espécie competidora.

O cultivar Fundacep 63RR tolera a interferência de 10 plantas $\mathrm{m}^{-2}$ de milho por 28 dias após a semeadura e de 30 plantas $\mathrm{m}^{-2}$ por 14 dias após a semeadura.

O cultivar Fundacep 59RR, tolera a interferência de 10 plantas $\mathrm{m}^{-2}$ por 42 dias após a semeadura e de 30 plantas $\mathrm{m}^{-2}$ por 28 dias.

\section{Referências}

BENEDETTI, J.G.R. et al. Período anterior a interferência de plantas daninhas em soja transgênica. Scientia Agraria, v.10, n.4, p.289295, 2009.

BIANCHI, M.A. et al. Interferência de Raphanus sativus na produtividade de cultivares de soja. Planta Daninha, v. 29, n. 4, p. 783-792, 2011.

BIANCHI, M.A.; FLECK, N.G.; FEDERIZZI, L.C. Características de plantas de soja que conferem habilidade competitiva com plantas daninhas. Bragantia, v.65, n.4, p.623-632, 2006.

CARVALHO, F.T.; VELINI, E.D. Período de interferência de plantas daninhas na cultura da soja. I - Cultivar IAC 11.Planta Daninha, v. 19, n.3, p. 317-322, 2001.

CENTRO ESTADUAL DE METEREOLOGIA - CEMETRS. Atlas Climático do Rio Grande

do Sul. Porto Alegre: Fundação Estadual de Pesquisa Agropecuária (FEPAGRO), 2011. v.1, 198p.

CHAUHAN, B.S. Phenotypic plasticity of blistering ammannia (Ammannia baccifera) in competition with direct-seeded rice. Weed Technology, v.27, n.2, p.373-377, 2013.

Empresa Brasileira de Pesquisa Agropecuária EMBRAPA. Sistema Brasileiro de Classificação de Solos. Rio de Janeiro: Embrapa Solos, 1999. 412p. (Embrapa Solos. Documentos, 15).

LAMEGO, F.P. et al. Tolerância à interferência de plantas competidoras e habilidade de supressão por genótipos de soja - II. Resposta de variáveis de produtividade. Planta Daninha, v.22, n.4, p.491-498, 2004.

MARQUARDT, P.; KRUPKE, C.; JOHNSON, W.G. Competition of transgenic volunteer corn with soybean and the effect on western corn rootworm emergence. Weed Science, v.60, n.2, p.193-198, 2012a. 
MARQUARDT, P.T. et al. Competitive effects of volunteer corn on hybrid corn growth and yield. Weed Science, v.60, n.4, p.537-541, 2012b.

MESCHEDE, D.K. et al. Período crítico de interferência de Euphorbia heterophyllana cultura da soja sob baixa densidade de semeadura. Planta Daninha, v.20, n.3, p.381387, 2002.

MORENO, J.A. Clima do Rio Grande do Sul. Porto Alegre: Secretaria da Agricultura, 1961. $41 \mathrm{p}$

NEPOMUCENO, $M$. et al. Períodos de interferência das plantas daninhas na cultura da soja nos sistemas de semeadura direta e convencional. Planta Daninha, v.25, n.1, p.4350, 2007.

PITELLI, R.A. Interferência de plantas daninhas em culturas agrícolas. Informe Agropecuário, v.11, p.16-27, 1985

RADOSEVICH, S.; HOLT, J.; GHERSA, C. Ecology of weeds and invasive plants: relationship to agriculture and natural resource management. 3ed. New York: Wiley, 2007. 589 p.

REUNIÃODE PESQUISADE SOJADA REGIÃO SUL, 38, 2009, Cruz Alta. Indicações técnicas para a cultura da soja no Rio Grande do Sul e em Santa Catarina 2010/2011 e 2011/2012. Cruz Alta: FUNDACEP, 2010. 168p.

SILVA, A.F. et al. Período anterior à interferência e componentes de produtividade da soja transgênica em função do método de semeadura. Scientia Agraria, v.10, n.6, p.489498, 2009b.

SILVA, A.F. et al. Período anterior à interferência na cultura da soja-RR em condições de baixa, média e alta infestação. Planta Daninha, v.27, n.1, p.57-66, 2009a.

STECKEL, L.E.; SPRAGUE, C.L. Late-season common waterhemp (Amaranthus rudis) interference in narrow-and wide-row soybean. Weed Technology, v.18, n.4, p.947-952, 2004. 